\title{
PELATIHAN PENGEMBANGAN MEDIA PEMBELAJARAN FLASH GURU SMA/SMK MUHAMMADIYAH SE- KABUPATEN GUNUNGKIDUL
}

\author{
Oleh: \\ Vita Istihapsari, Aan Hendroanto \\ Universitas Ahmad Dahlan, Jalan Prof. Dr. Soepomo, Yogyakarta \\ E-mail: vita.istihapsari@gmail.com \\ E-mail: aanhendroanto@gmail.com
}

\begin{abstract}
Ringkasan
Salah satu faktor yang sangat berpengaruh terhadap kualitas pendidikan adalah penggunaan media pembelajaran. Media pembelajaran yang baik akan membantu guru dalam menyelenggarakan proses pembelajaran yang baik pula serta membantu meningkatkan hasil belajar siswa. Salah satu media pembelajaran yang cukup populer saat ini yaitu media pembelajaran Flash. Media pembelajaran ini dinilai sangat baik untuk digunakan dalam kegiatan pembelajaran karena penggunaannya yang effisien dan effektif. Oleh karena itu, pelatihan pengembangan media pembelajaran flash perlu dilakukan pada guru-guru matematika. Artikel ini membahas tentang pengabdian kepada masyarakat berupa pelatihan pengembangan media pembelajaran flash bagi guru SMA/SMK se Kabupaten Gunungkidul. Metode pengabdian yang digunakan yaitu pelatihan dan workshop. Adapun hasil dari pelatihan yang telah dilaksanakan, dapat disimpulkan bahwa 1) pelatihan dan workshop berjalan dengan lancar dan baik, 2) respon perserta terhadap pelaksanaan pelatihan dan workshop termasuk dalam kategori baik dengan nilai rata-rata 4,2, 3) terdapat kendala berupa keterbatasan waktu pembuatan media pembelajaran flash dan minat guru dalam pembuatan media yang kurang, serta 4) jarak yang terlalu jauh membuat peserta sulit dalam berkoordinasi dengan anggota kelompoknya.
\end{abstract}

Kata Kunci: Pengabdian, Pelatihan dan Workshop, Media Pembelajaran Flash.

\section{Abstract}

One factor that is very influential on the quality of education is the use of learning media. Good learning media will help teachers in organizing a good learning process as well as help improve student learning outcomes. One of the learning media that is quite popular today is Flash learning media. Learning media is considered very good for use in learning activities because of its efficient and effective use. Therefore, the development training of flash learning media needs to be done on math teachers. This article discusses the dedication to the community in the form of training the development of flash learning media for high school teachers /SMK in Gunungkidul. The method of devotion used is training and workshop. As for the result of the training that has been implemented, it can be concluded that 1) the training and workshop run smoothly and well, 2) the participants' response to the training and workshop are included in good category with the average score 4,2,3) there are constraints in the form of limitations time of making of flash learning media and interest of teacher in making less media, and 4) distance too far make the participant difficult in coordinate with member of group.

Keywords: Devotion, Training and Workshop, Flash Learning Media.

\section{A. PENDAHULUAN}

Pendidikan merupakan kunci untuk meraih masa depan yang lebih baik. Dalam konteks bangsa dan negara, pendidikan merupakan investasi untuk mempersiapkan generasi muda dalam membangun, mengelola dan menjalankan negara. Oleh karena itu, kualitas pendidikan tidak boleh dipandang sebelah mata dan harus terus ditingkatkan agar masa depan kehidupan berbangsa, bernegara dan agama semakin baik. 
Kulitas pendidikan itu sendiri dapat dibedakan menjadi tiga hal yaitu 1) kurikulum, 2) lingkungan dan 3) proses pembelajaran. Pada poin 1 dan 2 kulitas pendidikan dapat dilakukan dengan cara meningkatkan fasilitas belajar yang mana telah banyak dilakukan oleh sekolah-sekolah maupun pemerintah. Namun, penguatan kualitas pada poin 3 yaitu proses pembelajaran masih sangat kurang dan perlu dilakukan lebih sering terutama di sekolah-sekolah Muhammadiyah.

Dalam proses pembelajaran, salah satu faktor yang sangat berpengaruh adalah media pembelajaran. Media pembelajaran yang baik akan membantu guru dalam menyelenggarakan proses pembelajaran yang baik pula. Salah satu media pembelajaran yang cukup populer saat ini yaitu media pembelajaran Flash. Media pembelajaran ini dinilai sangat baik untuk digunakan dalam kegiatan pembelajaran karena penggunaannya yang effisien dan effektif. Namun, proses pembuatan dan pengembangannya cukup sulit dan hanya beberapa guru saja yang memiliki keahlian tentang flash. Oleh karena itu, dalam rangka meningkatkan kualitas pendidikan di Yogyakarta khususnya di kabupaten Gunung Kidul, kami berencana untuk mengadakan pelatihan pengembangan media pembelajaran Flash. Harapannya, dengan pelatihan ini, guru-guru matematika di kabupaten Gunung Kidul mampu mengembangkan media pembelajarn Flash karya mereka sendiri sehingga dapat diterapkan dalam proses pembelajaran.

\section{B. METODE PELAKSANAAN}

Sasaran kegiatan ini adalah guru-guru SMA/ SMK Muhammadiyah seKabupaten Gunungkidul, DIY. Kegiatan ini diikuti oleh masing-masing 1 guru yang berasal dari 12 SMA/ SMK Muhammadiyah di Kabupaten Gunungkidul, dimana seluruh SMA/SMK di Kabupaten Gunungkidul terdapat 15 sekolahan.

Metode pelaksanaan pelatihan ini berupa workshop dan pelatihan. Pelatihan dilakukan untuk memberikan tambahan pengetahuan dan wawasan tentang media pembelajaran Flash. Adapun Workshop perlu dilakukan agar peserta dapat secara langsung mempraktekkan ilmu yang diperoleh dalam pembuatan media pembelajaran Flash. Kegiatan pengabdian selanjutnya berupa pendampingan.

Adapun materi dalam pelatihan ini terdiri dari 7 pertemuan yang terdiri dari kegiatan yang berbeda-beda. Dalam setiap kegiatan terdapat topik khusus yang akan dibahas untuk membantu guru meningkatkan pemahaman tentang media pembelajaran Flash. Adapun materi pada 7 pertemuan tersebut adalah sebagai berikut:

a. Pengenalan media pembelajaran Flash dan program Adobe Flash CS5 pada peserta

b. Pengenalan layer dan pembuatan animasi-animasi pada objek sederhana

c. Penggunaan Action Scripts dalam pembuatan animasi sederhana

d. Pembuatan gambar grafis, button, dan objek-objek sederhana dan animasinya

e. Pembuatan Grafis Multilayer dengan animasi-animasinya

f. Pembuatan media pembelajaran Flash sederhana

g. Pembuatan media pembelajaran Flash untuk topik tertentu 
Diterbitkan oleh Lembaga Pengabdian kepada Masyarakat

Universitas Ahmad Dahlan Yogyakarta

\section{HASIL DAN PEMBAHASAN}

Pelaksanaan pelatihan dan workshop media pembelajaran flash dilaksanakan pada tanggal 20 Mei 2017. Dari 15 sekolah yang diundang, hanya ada 10 peserta yang hadir dari 10 sekolah yang berbeda. Peserta dibekali ringkasan materi berupa modul dan software macromedia flash portable serta kit yang terdiri dari map, block note, dan flashdisk. Secara umum kegiatan berjalan dengan lancer tanpa kendala yang berarti. Selanjutnya peserta melaksanakan kegiatan mandiri pada bulan Juni - Juli. Sebagai kegiatan tindak lanjut pelatihan, dilaksanakan pula kunjungan pendampingan ke sekolah-sekolah sasaran untuk memantau perkembangan kegaitan mandiri pada tanggal 21 Juli 2017, tim pengabdian berkunjung ke tiga sekolah yaitu:

1) SMK Muhammadiyah 1 Patuk, 2) SMK Muhammadiyah 1 Playen, dan 3) SMK Muhammadiyah Wonosari.

Kegiatan pelatihan dan workshop dapat dikatakan berjalan dengan lancar dan baik, hal ini dapat dilihat pada hasil data umpan balik dari peserta dalam memberikan penilaian dari 1 (kualitas rendah) hingga 5 (kualitas tinggi) terhadap kegiatan pelatihan dan workshop sebagaimana disajikan pada Tabel 1 berikut.

Tabel 1. Umpan Balik Peserta Workshop

No. Aspek Respon Terbanyak Rata-rata

\begin{tabular}{|c|c|c|c|}
\hline \multicolumn{4}{|c|}{ Program Pelatihan } \\
\hline$\overline{1}$ & Kesesuaian Tema Pelatihan & 5 & 4,3 \\
\hline 2 & Ketercapaian Tujuan Pelatihan & 4 & 3,6 \\
\hline 3 & Ketepatan Jadwal & 4 & 4,1 \\
\hline 4 & Suasana Pelatihan Menyenangkan & 4 & 4 \\
\hline 5 & Pengalaman yang didapatkan & 4 & 4,1 \\
\hline \multicolumn{4}{|c|}{ Kualitas Narasumber } \\
\hline 6 & Penguasaan Materi & 4 & 4,3 \\
\hline 7 & Kemampuan Mengajar & 4 & 4,2 \\
\hline \multicolumn{4}{|c|}{ Fasilitas Pelatihan } \\
\hline 8 & Pelatihan Kit & 5 & 4,5 \\
\hline 9 & Konsumsi Peserta & 5 & 4,6 \\
\hline 10 & Media dan Alat Bantu & 5 & 4,5 \\
\hline \multicolumn{4}{|c|}{$\begin{array}{ll}\text { Rencana Tindak Lanjut } \\
\end{array}$} \\
\hline$\overline{11}$ & Kesanggupan Mengembangakan Media & 4 & 4,1 \\
\hline 12 & Perlunya Pendampingan & 4 & 4,3 \\
\hline & & ta-rata & 4,2 \\
\hline
\end{tabular}

Dari Tabel 1 di atas, pada setiap aspek memiliki rata-rata yang cukup tinggi dan masuk kategori "Baik". Dari aspek fasilitas yang disediakan, peserta menilai sudah baik dengan nilai terbanyak 4 dan rata-rata 4,5. Peserta juga memberikan nilai cukup tinggi untuk aspek kualitas narasumber dengan rata-rata nilai 4,2. Nilai terendah pada umpan balik peserta terdapat pada aspek ketercapaian tujuan pelatihan. Hal ini dikarenakan 
materi flash yang cukup sulit sehingga membutuhkan waktu lebih apalagi untuk mereka yang sudah tidak muda lagi. Alasan ini diperkuat dari hasil wawancara pada saat monitoring dilakukan.

Pada bagian rencana tindak lanjut, peserta menilai perlu adanya pendampingan lanjutan terlihat dari nilai rata-ratanya yaitu 4,1. Oleh karena itu, TIM membentuk kelompok berdasarkan kedekatan sekolah untuk membuat media pembelajaran flash. Dikarenakan jarak yang cukup jauh, pendampingan hanya dilakukan melalui WA dan Email. Namun pada akhir bulan Juli dilakukan monitoring dan pendampingan ke sekolahsekolah yang terpilih guna melihat perkembangan peserta pelatihan.

Berdasarkan wawancara terhadap guru saat kegiatan pendampingan, ditemukan beberapa kendala dalam pembuatan media pembelajaran flash oleh guru-guru SMA. Kendala yang paling banyak ditemui adalah keterbatasan waktu pembuatan. Hal ini bisa dimaklumi karena pembuatan media pembelajaran flash membutuhkan waktu yang cukup lama, mengingat detailnya dalam proses pembuatan. Namun secara umum, para guru telah membuat media pembelajaran tersebut dengan tampilan yang baik.

Adapun kendala-kendala yang dihadapi oleh guru-guru SMA/SMK Muhammadiyah diantaranya adalah 1) Sulitnya meluangkan waktu untuk membuat media pembelajaran flash, mengingat bulan Juni - Juli adalah bulan yang padat bagi sekolahan yaitu akhir dan awal tahun pelajaran serta bersamaan dengan bulan Ramadhan, 2) Tidak adanya tuntutan dari pihak sekolah untuk membuat media pembelajaran, sehingga minat untuk berinovasi dengan media pembelajaran pun berkurang, 3) Kemampuan beberapa laptop peserta yang kurang bagus krn proses pembuatan macromedia flash membutuhkan memori yang cukup besar serta 4) jarak sekolah yang berjauhan membuat koordinasi menjadi sulit.

\section{KESIMPULAN DAN SARAN}

Kesimpulan yang dapat diambil dari kegiatan ini adalah 1) pelatihan dan workshop pengembangan media pembelajaran flash berjalan dengan lancar dan baik, 2) respon perserta terhadap pelaksanaan pelatihan dan workshop termasuk dalam kategori baik berdasarkan perhitungan angket respon di atas, 3) terdapat kendala berupa keterbatasan waktu pembuatan media pembelajaran flash dan minat guru dalam pembuatan media yang kurang, serta 4) jarak yang terlalu jauh membuat peserta sulit dalam berkoordinasi dengan anggota kelompoknya.

Saran yang dapat direkomendasikan adalah 1) pelatihan pengembangan media pembelajaran flash perlu dilakukan lagi karena materi yang cukup detail dan sulit, 2) memberikan motivasi kepada guru baik dari panitia pelaksana maupun dari PDM setempat agar guru-guru lebih giat dalam mengikuti kegiatan, 3) perlu adanya dukungan materiil ataupun non materiil untuk transportasi selama pelatihan di daerah seperti Gunungkidul karena medan yang tidak biasa. 
Diterbitkan oleh Lembaga Pengabdian kepada Masyarakat

Universitas Ahmad Dahlan Yogyakarta

\section{DAFTAR PUSTAKA}

Kemdikbud. 2014. Permendikbud nomor 58 tahun 2014. Jakarta: Kmdikbud.

Maizora, S. 2010. Pembuatan Media Pembelajaran dengan Menggunakan Macromedia Flash8. Tersedia di: https://syafdiichiemaizora.files.wordpress.com/2011/01 /pengenalan-flash.pdf

Rossnan, Sarah. 2006. Overcoming Math Anxiety. Mathitudes. Palm Beach County School 
